\title{
Desfolha e posição do fruto em meloeiro cv. Don Luis, cultivado em ambiente protegido
}

\author{
Aline da Silva Bhering ${ }^{1}$, Mário Puiatti², Nelson Licínio Campos Oliveira ${ }^{3}$, Paulo Roberto Cecon ${ }^{4}$
}

\section{RESUMO}

Este trabalho teve como objetivo avaliar o efeito do número de folhas e da posição de fixação do fruto na planta sobre a produção de biomassa e a qualidade de frutos de meloeiro tipo Cantaloupe. O experimento foi constituído de quatro tratamentos, delineamento inteiramente casualizado, com 15 repetições. Os tratamentos foram: 1) 14 folhas/ planta, com fruto fixado na posição intermediária da planta; 2) 14 folhas/planta, com fruto fixado no alto da planta; 3 ) 14 folhas/planta até a fixação do fruto no alto da planta, quando foram retiradas as sete folhas imediatamente abaixo do fruto; e 4) 14 folhas/planta até a fixação do fruto no alto da planta, quando foram retiradas as sete folhas na base da planta. Avaliaram-se: área foliar; área foliar específica; razão de área foliar; dias para colheita; ciclo cultural; diâmetro, comprimento, massa da matéria fresca, espessura do pericarpo, diâmetro da cavidade e teor de sólidos solúveis de fruto; e massa da matéria seca de folhas, caule, pecíolo e fruto. A condução das plantas com maior número de folhas (tratamentos 1 e 2) proporcionou maior área foliar, massa da matéria seca de folhas, massa das matérias fresca e seca de fruto, espessura do pericarpo e sólidos solúveis de fruto, comparado aos tratamentos 3 e 4 . Maior área foliar/fruto proporciona frutos com maiores massa, espessura de pericarpo e teor de sólidos solúveis. A fixação do fruto na porção intermediária, comparada à fixação no topo da planta, tem como vantagem o menor ciclo cultural. O meloeiro ajusta a produção de massa dos órgãos à área foliar disponível na planta.

Palavras-chave: Cucumis melo, podas, fonte-dreno, área foliar específica, produtividade.

\section{ABSTRACT \\ Defolation and position of fruit in melon plants cv. Don Luis, cultivated in protected environment}

The study aimed to evaluate the effect of leaf number and fruit setting position in the plant on the production of biomass and fruit quality of melon Cantaloupe. The experiment consisted of four treatments, in a completely randomized design with 15 replications. The treatments were: 1) 14 leaves per plant, with the fruit set in the middle portion of the plant; 2) 14 leaves per plant, with fruit set in the top of the plant; 3) 14 leaves per plant until the fruit set on the top of the plant when seven leaves were immediately removed below the fruit and 4) 14 leaves per plant until the fruit set on top of the plant when seven leaves were removed from the plant base. The following traits were evaluated: leaf area; specific leaf area; leaf area ratio; days to harvest; cultural cycle; diameter, length, fresh matter, pulp thickness, cavity diameter and soluble solids content of the fruit; leaves, stem, petiole and fruit dry weight. The management of plants with higher leaf number (treatments 1 and 2) showed higher leaf area, dry weight of leaves, fresh matter, dry weight, pericarp thickness and soluble solids content of the fruit, compared with other treatments. Larger leaf area/fruit

Recebido para publicação em 15/04/2011 e aprovado em 20/09/2012

${ }^{1}$ Graduanda em Agronomia. Universidade Federal de Viçosa, Campus Viçosa, Avenida Peter Henry Rolfs, s/n, 36570-000, Viçosa, Minas Gerais, Brasil. Bolsista IC. alinebhering@hotmail.com (autora para correspondência).

${ }^{2}$ Engenheiro-Agrônomo, Doutor. Departamento de Fitotecnia, Universidade Federal de Viçosa, Campus Viçosa, Avenida Peter Henry Rolfs, s/n, 36570-000, Viçosa, Minas Gerais, Brasil. mpuiatti@ufv.br

${ }^{3}$ Licenciado em Ciências Agrícolas, Doutor. Instituto Federal de Educação, Ciência e Tecnologia do Norte de Minas, Campus Montes Claros, Rua Dois, 300, 39404-058, Montes Claros, Minas Gerais, Brasil.nelsonlco@yahoo.com.br

${ }^{4}$ Engenheiro-Agrônomo, Doutor. Departamento de Estatística, Universidade Federal de Viçosa, Campus Viçosa, Avenida Peter Henry Rolfs, s/n, 36570-000, Viçosa, Minas Gerais, Brasil. cecon@ufv.br

Rev. Ceres, Viçosa, v. 60, n.1, p. 066-071, jan/fev, 2013 
provides fruits with greater mass, pericarp and soluble solids content. The fixing of the fruit in the middle portion, compared with setting at the top of the plant, has the advantage of the shorter cultural cycle. Melon plants adjust the mass production of organs matter to the leaf area available in the plant.

Key words: Cucumis melo, pruning, sink-source, specific leaf area, yield.

\section{INTRODUÇÃO}

O cultivo do meloeiro (Cucumis melo L.) no Sudeste do Brasil só é possível de ser realizado durante o período do verão, em razão da necessidade da planta em temperatura e radiação solar elevada. Todavia, esse período, nessa região, caracteriza-se por apresentar alto índice pluvial, promovendo o aumento da umidade do solo e da umidade relativa do ar. Essas condições favorecem o aparecimento de doenças e de pragas que causam redução da área foliar, resultando em frutos pequenos, defeituosos, com baixo teor de açúcares e, portanto, baixas produtividades da cultura e dos frutos (Coelho et al., 2003). Por essas razões, o cultivo do meloeiro, sobretudo de melões tipo Cantaloupe (Cucumis melo L. grupo Cantalupensis), no Sudeste do Brasil somente se torna viável com a proteção de plantas (Queiroga et al., 2008a,b).

Todavia, o cultivo do meloeiro em ambiente protegido requer o desenvolvimento de técnicas para sua exploração, como o manejo das plantas via podas. A poda consiste na alteração da razão fonte-dreno que, no meloeiro, pode ser alterada com a retirada de hastes e/ou com o desbaste de frutos (raleio), variando o número de folhas por planta e por fruto e, consequentemente, a área foliar (fonte) e o tamanho da demanda por fotoassimilados (dreno), alterando o particionamento de assimilados (Valentin et al., 2006; Queiroga et al., 2008a; 2009). Todavia, a determinação da altura da capação (número de folhas) e da posição de fixação dos frutos é de extrema importância no manejo da cultura do meloeiro em ambiente protegido (Queiroga et al., 2008c; 2009).

$\mathrm{O}$ meloeiro em ambiente protegido responde às alterações na relação entre fonte-dreno. Nessa espécie a remoção de frutos e/ou o aumento da área foliar por fruto permite à planta direcionar os fotoassimilados disponíveis para os frutos remanescentes, incrementando a massa média e a qualidade desses (Valentin et al., 1998; 2006; Queiroga et al., 2008a,b,c; 2009). Todavia, visto que os cultivares dentro de um mesmo grupo apresentam comportamento diferenciado às podas (Queiroga et al., 2008a; 2009), o entendimento do particionamento de fotoassimilados e da alocação de massa na planta com a finalidade de se encontrar o equilíbrio da relação fonte-dreno é importante para cada variedade.
Portanto, torna-se de fundamental importância o conhecimento sobre a poda do meloeiro visando o seu cultivo, sobretudo, em ambiente protegido, de forma a facilitar o manejo da cultura sem, contudo, causar redução da produtividade e da qualidade de frutos (Queiroga et al., 2008a,b,c; 2009).

Este trabalho teve como objetivo avaliar a produção de biomassa e a qualidade de frutos do meloeiro cv. Don Luis, em razão de desfolhas e da posição do fruto na planta, cultivado em ambiente protegido.

\section{MATERIAL E MÉTODOS}

Este experimento foi conduzido em casa de vegetação no Departamento de Fitotecnia da Universidade Federal de Viçosa (UFV, 2048'07"S and 42 51 '31"W, $680 \mathrm{~m}$ ) em vasos plásticos pretos de $11,0 \mathrm{dm}^{3}$ de capacidade. $\mathrm{O}$ substrato para preenchimento dos vasos foi um solo Argissolo Vermelho-Amarelo câmbico, classe textural argilo-arenoso, que apresentava as seguintes características químicas: $\mathrm{pH}_{\text {(Água) }}=5,8 ; \mathrm{P}=14 ; \mathrm{e} \mathrm{K}=44 \mathrm{mg} \mathrm{dm}^{-3} ; \mathrm{Ca}^{2+}$ $=2,3 ; \mathrm{Mg}^{2+}=0,5 ; \mathrm{Al}^{3+}=0,0 ;(\mathrm{H}+\mathrm{Al})=1,65 ; \mathrm{SB}=2,91$; $\mathrm{CTC}_{(\mathrm{t})}=2,91 \mathrm{e} \mathrm{CTC}_{(\mathrm{T})}=4,56 \mathrm{cmol}_{\mathrm{c}} \mathrm{dm}^{-3} ; \mathrm{V}=64 \% ; \mathrm{MO}=$ 0,9 dag $\mathrm{kg}^{-1}$ e P-rem $=23,6 \mathrm{mg} \mathrm{L}^{-1}$. A correção do solo e a fertilização da cultura foram realizadas com base na análise do solo e recomendações para a cultura, conforme Ribeiro et al. (1999).

Aos 50 dias antes do transplante das mudas, procedeu-se a correção do solo com calcário dolomítico, com base na saturação por bases, elevando-se a saturação para $80 \%$. Cinco dias antes do transplante das mudas procedeu-se a adubação de plantio. A dose total aplicada de cada nutriente em cada vaso foi de $1,65 \mathrm{~g}$ de $\mathrm{N} ; 1,32 \mathrm{~g}$ de $\mathrm{P}_{2} \mathrm{O}_{5} ; 2,64 \mathrm{~g}$ de $\mathrm{K}_{2} \mathrm{O} ; 82,5 \mathrm{mg}$ de $\mathrm{ZnSO}_{4} ; 55,0 \mathrm{mg}$ de bórax; 55,0 mg de $\mathrm{CuSO}_{4}$ e 3,81 mg de $\mathrm{Na}_{2} \mathrm{MoO}_{4} \cdot 2 \mathrm{H}_{2} \mathrm{O}$. As fontes para $\mathrm{N}$, P e K foram ureia, superfosfato simples e cloreto de potássio, respectivamente.

Exceto $\mathrm{Ne} \mathrm{K}$, os demais nutrientes foram aplicados na sua totalidade no plantio. Da dose total de $\mathrm{N}$ e $\mathrm{K}$ foram utilizados, no plantio, 20 e 10\%, respectivamente; o restante foi aplicado semanalmente, via fertirrigação, manualmente, iniciando-se uma semana após transplante das mudas. Em cada fertirrigação foram utilizados os seguintes percentuais de $\mathrm{Ne} \mathrm{K}: 1^{\mathrm{a}}=10$ e $5 \% ; 2^{\mathrm{a}}=10$ e $5 \% ; 3^{\mathrm{a}}=12$

Rev. Ceres, Viçosa, v. 60, n.1, p. 066-071, jan/fev, 2013 
e $5 \% ; 4^{a}=12$ e $10 \% ; 5^{a}=12$ e $10 \% ; 6^{a}=6$ e $10 \% ; 7^{a}=6$ e $10 \% ; 8^{a}=0$ e $15 \% ; 9^{a}=6$ e $10 \%$; e $10^{a}=6$ e $10 \%$, respectivamente. As irrigações foram diárias, feitas de forma manual, de forma a saturar o solo. Foram colocados sob os vasos pratos plásticos com a função de coletar eventual solução drenada do vaso, a qual era recolhida e, posteriormente, vertida na parte superior do vaso.

Utilizou-se o cv. Don Luis (Sakata Seed Sudamerica Ltda.), do tipo Cantaloupe, que apresenta frutos de casca amarelada com ótima formação de rede, pericarpo alaranjado intenso e ótimo sabor, massa média de $1 \mathrm{~kg} /$ fruto, com início de colheita entre 65 a 75 dias (Sakata, 2009). A semeadura foi realizada em bandejas de poliestireno com 128 células, preenchidas com substrato agrícola comercial, em 17/09/2008. Aos 25 dias após a semeadura, com as mudas apresentando a segunda folha em expansão, foi realizado o transplante para os vasos de cultivo, os quais foram dispostos sobre bancadas (estrados de madeira), em duas fileiras, de forma que as plantas ficaram espaçadas de 1,0 x 0,30 m (entre e dentro da fileira). O experimento foi constituído de quatro tratamentos, dispostos no delineamento inteiramente casualizado, com 15 repetições, tendo cada repetição sido constituída de um vaso contendo uma planta com apenas um fruto. A bordadura foi constituída de um vaso de cada fileira, nas extremidades das bancadas. As plantas foram conduzidas com apenas a haste principal, e todas as demais ramificações e frutos foram retirados.

Os tratamentos foram: 1- planta com 14 folhas, sendo o fruto fixado na porção intermediária (sete folhas abaixo e sete folhas acima do fruto); 2- planta com 14 folhas, sendo o fruto fixado no alto da planta ( 14 folhas abaixo do fruto); 3- planta com 14 folhas até a fixação do fruto no alto da planta, quando foram retiradas as sete folhas imediatamente abaixo do fruto (fruto no alto com sete folhas na base da planta); e 4- planta com 14 folhas até a fixação do fruto no alto, quando foram retiradas as sete folhas na base da planta (fruto no alto com sete folhas imediatamente abaixo). Todas as plantas foram capadas (retirada da gema apical do caule) quando tinham 14 folhas. Nos tratamentos 3 e 4 , as folhas foram retiradas (limbo), cortando-se o pecíolo com lâmina desinfestada em solução de hipoclorito de sódio a $2 \%$, deixando-se $2 / 3$ do pecíolo para evitar a penetração de possíveis patógenos no caule (haste).

As plantas foram conduzidas verticalmente, em haste única, fixadas em bambu fincado em cada vaso. Durante o ciclo da cultura foram feitas três pulverizações com inseticida à base de neonicotinoides para controle da moscabranca. A partir da antese das flores hermafroditas, realizou-se a polinização manualmente em razão da baixa atividade de abelhas melíferas no ambiente, registrando-se a data da antese de cada flor. Durante o desenvolvimento, cada fruto foi envolto em saco telado fixado no tutor, de forma a evitar danos provocados por possível queda no caso de ocorrer a abscisão do pedúnculo. A colheita dos frutos foi realizada à medida que eles apresentavam 90\% da camada de abscisão do pedúnculo formada.

Os valores de temperatura e de insolação (horas de brilho solar) registrados durante a condução do experimento encontram-se na Figura 1. As temperaturas máxima e mínima foram registradas diariamente em termômetro de máxima e de mínima colocados à altura do dossel das plantas. Os dados de insolação foram registrados pela estação meteorológica do Departamento de Engenharia Agrícola/UFV.

$\mathrm{Na}$ colheita avaliaram-se: área foliar da planta (AF $\mathrm{cm}^{2}$ planta $\left.^{-1}\right)$; massa das matérias fresca e seca de fruto ( $\mathrm{g}$ fruto $\left.^{-1}\right)$; diâmetro do fruto $(\mathrm{cm})$; comprimento do fruto $(\mathrm{cm})$; razão de formato de fruto ( $\mathrm{RF}=$ comprimento/largura); espessura do pericarpo $(\mathrm{cm})$; diâmetro da cavidade do fruto $(\mathrm{cm})$; sólidos solúveis ( $\left.{ }^{\circ} \mathrm{Brix}\right)$; massa da matéria seca de caule (haste), folhas e pecíolos; área foliar específica (AF/massa da matéria seca de folha); razão de área foliar (AF / massa da matéria seca total da planta); dias da antese até a colheita; e ciclo cultural (dias da semeadura até a colheita do fruto). Todos os frutos colhidos foram considerados comerciais (firmes, uniformes quanto à cor, com bom rendilhamento de casca, sem deformações, murchamento, rachaduras e sinais de podridão, ataque de insetos-pragas e de danos mecânicos).

Os dados obtidos foram submetidos à análise de variância e as médias dos tratamentos, comparadas pelo teste de Tukey a $5 \%$ de probabilidade.

\section{RESULTADOS E DISCUSSÃO}

Na Tabela 1 são apresentados os valores obtidos para todas as características avaliadas. A condução das plantas com maior número de folhas (14 folhas/planta - tratamentos 1 e 2) proporcionou maior área foliar por planta, massa de matéria seca de folha (limbo) e frutos com maiores valores de diâmetro, espessura do pericarpo, teor de sólidos solúveis e de massa de matérias fresca e seca, comparado aos tratamentos com menor número de folhas (sete folhas/planta - tratamentos 3 e 4). Queiroga et al. (2008a) também obtiveram, com o cv. Coronado, com poda apical com 28 folhas conduzida com um ou dois frutos por planta, maiores índices de área foliar, massa de matéria seca de caule e de folhas e massa média de fruto em plantas conduzidas com apenas um fruto, comparado a plantas com dois frutos; todavia, com o cv. Torreon os efeitos foram menos expressivos, evidenciando a existência de efeito varietal. Maior espessura do pericarpo em melão é desejável, pois é a parte comestível do fruto; também temse observado relação direta entre espessura do pericarpo 
e massa média de fruto em razão do maior acúmulo de fotoassimilados no pericarpo resultar, proporcionalmente, em menor cavidade interna (Long et al., 2004).

Os maiores valores de massa obtidos nas plantas com maior número de folhas podem ser explicados pela relação fonte-dreno, a exemplo de Valentin et al. (1998; 2006), que observaram menor área foliar e aceleração da senescência foliar ao aumentar o número de drenos (frutos) na planta, devido à grande demanda por fotoassimilados que ocorre entre frutos e demais drenos (folhas e ramificações novas).

Correlações positivas e significativas entre a área foliar com massa de fruto e o teor de sólidos foram encontradas no cv. Torreon por Queiroga et al. (2008b). Com esse mesmo cultivar, Queiroga et al. (2008c) obtiveram resposta linear crescente em área foliar, massa de fruto e produtividade comercial ao incrementar de 16 para 25 o número de folhas/planta. Portanto, quando há descompensação entre os órgãos que atuam como fonte e dreno no meloeiro, como no caso dos tratamentos 3 e 4 deste trabalho, há reflexo negativo na massa e no teor de sólidos solúveis dos frutos.

A antese das flores do tratamento 1 ocorreu dos 36 aos 41 DAT, e a colheita dos frutos entre 85 e 90 DAT. Nos demais tratamentos, a antese aconteceu entre 49 e 53 DAT e a colheita entre 90 e 96 DAT (Figura 1). Ao comparar as plantas com fixação do fruto na posição intermediária da planta (trat. 1) com os demais tratamentos, verificou-se que a fixação do fruto na posição intermediária resultou em maior número de dias da antese à colheita e menor ciclo cultural (Tabela 1). O maior período de tempo da antese à colheita desse tratamento pode ser explicado pela competição por fotoassimilados entre o fruto em crescimento com as folhas novas e a gema apical do caule também em crescimento. Atraso na maturação dos frutos com prolongamento do ciclo também foi observado por Barni et al. (2003) em plantas com maior número de ramificações. Além disso, os frutos dessas plantas passaram por período de tempo mais longo em condições de baixa insolação, comparado aos demais tratamentos com frutos fixados na parte superior da planta (Figura 1). Em melão, a baixa radiação solar limita o crescimento das plantas, a produção e a qualidade dos frutos, por lhes restringir a disponibilidade de fotoassimilados (Nishizawa et al., 1998; 2000; Pereira et al., 2010; Sang Gyu et al., 2003). Por sua vez, o menor ciclo cultural para esse tratamento ocorreu em razão da posição dos frutos na porção intermediária cuja antese se iniciou com cerca de 12 dias de antecedência aos demais tratamentos (Figura 1).

$\mathrm{O}$ período da antese à colheita dos frutos variou de 40 a 49 dias e o ciclo cultural de 109 a 115 (Tabela 1). Esses períodos de tempo são excessivamente longos se comparados a cultivos em regiões do Nordeste brasileiro, onde o período da antese à colheita varia de 30 a 35 e o ciclo cultural de 60 a 65 dias e (Silva e Costa, 2003). A explicação para os resultados observados neste trabalho está na

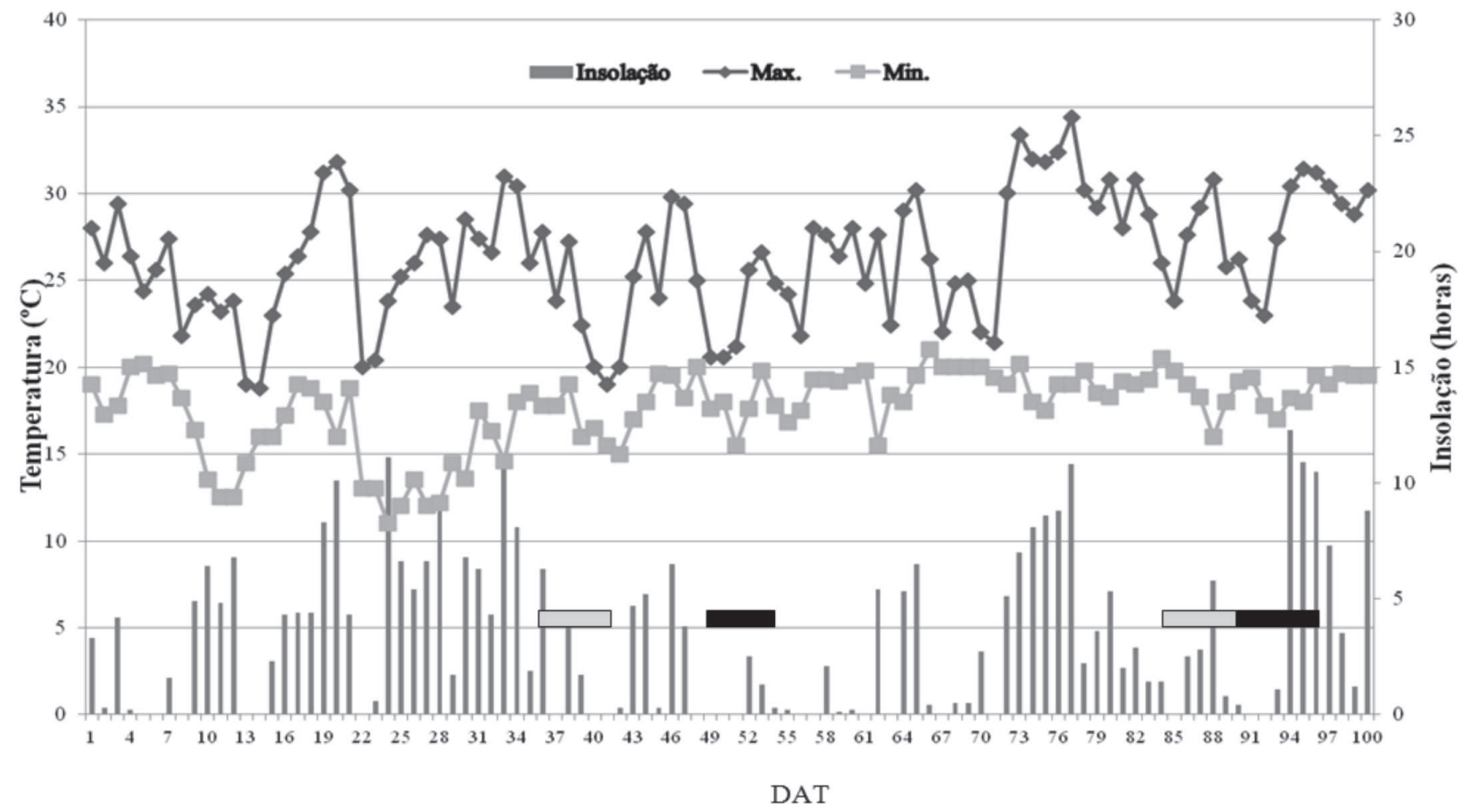

Figura 1. Valores diários de temperaturas máxima (Máx.) e mínima (Mín.) e de horas Insolação durante o período de cultivo do melão Cantaloupe em casa de vegetação em dias após o transplante (DAT). Barras horizontais representam o intervalo de duração da antese e da colheita dos frutos do tratamento 1 ( $\square$ ) e dos tratamentos 2,3 e 4(ש), respectivamente. 
temperatura e irradiância (insolação) relativamente baixas no período do início da antese (36 DAT) até cerca dos 71 DAT e posterior aos 78 DAT (Figura 1). O valor diário médio de insolação nesse período foi de apenas $1,8 \mathrm{~h}$, e está muito abaixo da insolação média diária observada na região semiárida do Nordeste brasileiro, a qual é responsável por mais de $90 \%$ da produção de melão no Brasil, que está em torno de 9 h (Silva e Costa, 2003).

Frutos do tratamento 2 apresentaram maior comprimento do que os dos demais tratamentos e maior razão de formato e diâmetro da cavidade interna comparado aos frutos do tratamento 1 (Tabela 1). Essas alterações são de difícil explicação, visto que o formato de fruto do meloeiro, além de ser uma característica varietal, altera-se em razão da poda, todavia sem padrão definido de resposta (Rizzo e Braz, 2004; Queiroga et al., 2008b). Contudo, fruto com menor cavidade interna é uma característica de interesse, pois, proporcionalmente, está associado à maior espessura de pericarpo (Long et al., 2004), enquanto frutos com razão de formato próximo à unidade são preferidos no processo de embalagem, por acomodarem melhor nas caixas de papel (Rizzo e Braz, 2004; Queiroga et al., 2008b).

Ao comparar as plantas com apenas sete folhas, alterando apenas a posição das folhas que permaneceram nas plantas (tratamentos 3 e 4), observa-se que não houve diferença significativa entre esses tratamentos para as características avaliadas, exceto para sólidos solúveis, com maior valor no tratamento 4 . Esse maior valor de sólidos solúveis no tratamento 4 pode ser explicado pela posição dos frutos mais próximos das folhas (fonte) e em razão dessas estarem mais ativas fisiologicamente do que as folhas do tratamento 3, uma vez que estas se situavam na porção basal das plantas, com idade mais avançada, justamente no estádio de crescimento do fruto.

Apesar da maior área foliar proporcionada pelos tratamentos com 14 folhas/planta, a área foliar específica e a razão de área foliar não diferiram entre os quatro tratamentos. A ausência de diferença no tocante à área foliar específica evidencia que as folhas do meloeiro não variaram a sua expansão em decorrência da variação no número de folhas. Por outro lado, a ausência de diferença no tocante à razão de área foliar evidencia que o meloeiro ajusta a produção de massa à área foliar disponível em cada planta, uma vez que nos tratamentos 3 e 4 a área foliar foi menor, mas a massa produzida pelos órgãos também o foi. Esses resultados evidenciam a importância do número de folhas/planta em meloeiro, visto que a planta demonstra pouca flexibilidade em ajustar a área foliar às condições de manejo da poda.

Ao comparar os resultados obtidos neste trabalho com os de outros com poda em meloeiro, observa-se que existe diferença comportamental entre cultivares de meloeiro quanto ao manejo da planta via podas, mesmo entre aqueles pertencentes ao mesmo grupo, como é o caso do Coronado, Torreon e Don Luis. Esses resultados eviden-

Tabela 1. Características avaliadas em meloeiro cv. Don Luis cultivado em ambiente protegido, submetido a desfolhas, e em razão da posição de fixação do fruto na planta

\begin{tabular}{|c|c|c|c|c|c|}
\hline \multirow{2}{*}{ Característica } & \multicolumn{4}{|c|}{ Tratamento } & \multirow{2}{*}{ CV \% } \\
\hline & 1 & 2 & 3 & 4 & \\
\hline Área foliar da planta $\left(\mathrm{cm}^{2}\right.$ planta $\left.{ }^{-1}\right)$ & $1958,8 \mathrm{a}$ & 2036,8 a & $1082,8 \mathrm{~b}$ & $1093,9 \mathrm{~b}$ & 10,7 \\
\hline Área foliar específica $\left(\mathrm{cm}^{2} \mathrm{~g}^{-1}\right.$ de matéria seca do limbo) & $260,6 \mathrm{a}$ & $262,2 \mathrm{a}$ & $275,8 \mathrm{a}$ & $272,0 \mathrm{a}$ & 22,1 \\
\hline Razão de área foliar ( $\mathrm{cm}^{2} \mathrm{~g}^{-1}$ de matéria seca da planta) & 298,36 a & $308,12 \mathrm{a}$ & $303,28 \mathrm{a}$ & $301,31 \mathrm{a}$ & 19,7 \\
\hline Massa da matéria seca de folha (limbo) (g planta $\left.{ }^{-1}\right)$ & $7,59 \mathrm{a}$ & $7,77 \mathrm{a}$ & $4,19 \mathrm{~b}$ & $4,23 \mathrm{~b}$ & 16,8 \\
\hline Massa da matéria seca de caule (haste) g planta ${ }^{-1}$ & $2,25 \mathrm{a}$ & $2,93 \mathrm{a}$ & $2,50 \mathrm{a}$ & $2,72 \mathrm{a}$ & 42,9 \\
\hline Massa da matéria seca de pecíolo (g planta ${ }^{-1}$ ) & $1,11 \mathrm{ab}$ & $1,24 \mathrm{a}$ & $0,61 \mathrm{~b}$ & $0,75 \mathrm{ab}$ & 59,4 \\
\hline Dias da antese à colheita & $49,0 \mathrm{a}$ & $42,7 \mathrm{~b}$ & $40,3 \mathrm{~b}$ & $42,5 \mathrm{~b}$ & 6,5 \\
\hline Ciclo cultural (dias) & $109,5 \mathrm{~b}$ & $114,8 \mathrm{a}$ & $112,5 \mathrm{a}$ & $112,1 \mathrm{ab}$ & 2,5 \\
\hline Comprimento do fruto $(\mathrm{cm})$ & $10,11 \mathrm{~b}$ & $10,83 \mathrm{a}$ & $10,08 \mathrm{~b}$ & $10,27 \mathrm{~b}$ & 4,8 \\
\hline Diâmetro do fruto $(\mathrm{cm})$ & $9,25 \mathrm{a}$ & $9,30 \mathrm{a}$ & $8,56 \mathrm{~b}$ & $8,63 \mathrm{~b}$ & 3,6 \\
\hline Razão de formato de fruto (comprimento/diâmetro) & $1,09 \mathrm{~b}$ & $1,17 \mathrm{a}$ & $1,18 \mathrm{a}$ & $1,19 \mathrm{a}$ & 4,5 \\
\hline Espessura do pericarpo $(\mathrm{cm})$ & $2,42 \mathrm{a}$ & $2,25 \mathrm{a}$ & $1,89 \mathrm{~b}$ & $1,91 \mathrm{~b}$ & 9,9 \\
\hline Diâmetro da cavidade do fruto $(\mathrm{cm})$ & $3,57 \mathrm{~b}$ & $4,03 \mathrm{a}$ & $3,81 \mathrm{ab}$ & $3,93 \mathrm{ab}$ & 9,8 \\
\hline Sólidos Solúveis ( ${ }^{\circ}$ Brix) & $7,7 \mathrm{a}$ & $7,2 \mathrm{ab}$ & $5,5 \mathrm{c}$ & $6,7 \mathrm{~b}$ & 12,3 \\
\hline Massa da matéria fresca de fruto $\left(\mathrm{g}_{\text {fruto }}{ }^{-1}\right)$ & $486,71 \mathrm{a}$ & 514,58 a & 394,06 b & $410,88 \mathrm{~b}$ & 9,2 \\
\hline Massa da matéria seca de fruto ( $\mathrm{g}_{\text {fruto }}{ }^{-1}$ ) & $34,36 \mathrm{a}$ & $30,78 \mathrm{a}$ & $24,34 \mathrm{~b}$ & $25,83 \mathrm{~b}$ & 17,9 \\
\hline
\end{tabular}

Médias na linha, seguidas por uma mesma letra, não diferem entre si pelo teste de Tukey a 5\% de probabilidade.

Tratamentos: 1- planta com 14 folhas, sendo o fruto fixado no meio (sete folhas abaixo e sete folhas acima do fruto); 2- planta com 14 folhas, sendo o fruto fixado no alto (14 folhas abaixo do fruto); 3- planta com 14 folhas até a fixação do fruto no alto, quando foram retiradas as sete folhas imediatamente abaixo do fruto (fruto no alto com sete folhas na base da planta); e 4- planta com 14 folhas até a fixação do fruto no alto, quando foram retiradas as sete folhas na base da planta (fruto no alto com sete folhas imediatamente abaixo). 
ciam a necessidade de se pesquisar cada cultivar de meloeiro em ambientes protegidos, para manejá-lo mais adequadamente. Para o cv. Don Luis, 14 folhas por planta parece ter sido insuficiente, visto que a massa média de fruto alcançada ficou em torno de $50 \%$ do informado pelo produtor das sementes (Sakata, 2009). Incrementos lineares em produtividade e qualidade de frutos foram observados com o cv. Coronado ao elevar de 16 para 25 o número de folhas por planta (Queiroga et al., 2008c; 2009), evidenciando a importância do manejo da área foliar para melhor desempenho produtivo do meloeiro.

Os baixos valores de massa média e de sólidos solúveis dos frutos obtidos neste trabalho, mesmo nas plantas com maior número de folhas, podem ser atribuídos à grande incidência de mosca-branca durante o ciclo, com dificuldades de seu controle, associado aos baixos valores de insolação diária durante o ciclo e valores de temperatura muito elevada dos 72 aos 82 DAT, fase final de crescimento e de maturação dos frutos (Figura 1).

\section{CONCLUSÕES}

A área foliar por planta e/ou por fruto, bem como a posição de fixação do fruto, é fator importante para a produção e qualidade de frutos do meloeiro.

Maior área foliar/fruto proporciona frutos com maiores massa, espessura de pericarpo e teor de sólidos solúveis.

A fixação do fruto na porção intermediária, comparada à fixação no topo da planta, tem como vantagem o menor ciclo cultural.

O meloeiro ajusta a produção de massa dos órgãos à área foliar disponível na planta.

\section{AGRADECIMENTO}

À FAPEMIG, pela Bolsa de IC concedida ao primeiro autor e pelo suporte financeiro para a publicação deste artigo.

\section{REFERÊNCIAS}

Barni V, Barni NA \& Silveira JRP (2003) Meloeiro em estufa: duas hastes é o melhor sistema de condução. Ciência Rural, 33:10391043.

Coelho EV, Fontes PCR \& Cardoso AA (2003) Qualidade do fruto de melão rendilhado em função de doses de nitrogênio. Bragantia, 62:173-178.

Long RL, Walsh KB, Rogers G \& Midmore DJ (2004) Source-sink manipulation to increase melon (Cucumis melo $\mathrm{L}$.) fruit biomass and soluble sugar content. Australian Journal of Agricultural Research, 55:1241-1251.

Nishizawa T, Ito A, Motomura Y, Ito M \& Togashi M (2000) Changes in fruit quality as influenced by shading of netted melon plants (Cucumis melo L. 'Andesu' and 'Luster'). Journal of the Japanese Society for Horticultural Science, 69:563-569.
Nishizawa T, Taira S, Nakanishi M, Ito M, Togashi M \& Motomura Y (1998) Acetaldehyde, ethanol, and carbohydrate concentrations in developing muskmelon fruit (Cucumis melo L. cv. Andesu) are affected by short-term shading. HortScience, 33:992-994

Pereira FHF, Puiatti M, Finger FL, Cecon PR \& Aquino LA (2010) Produção e qualidade de frutos de melões amarelo e charentais cultivados em ambientes sombreados. Revista Brasileira de Engenharia Agrícola e Ambiental, 14:944-950.

Queiroga RCF, Puiatti M, Fontes PCR \& Cecon PR (2008a) Partição de assimilados e índices fisiológicos de cultivares de melão do grupo Cantalupensis influenciados por número e posição de frutos na planta, em ambiente protegido. Revista Ceres, 55:596604 .

Queiroga RCF, Puiatti M, Fontes PCR \& Cecon PR (2008b) Produtividade e qualidade do melão cantaloupe, cultivado em ambiente protegido, variando o número de frutas na planta. Bragantia, 67:911-920.

Queiroga RCF, Puiatti M, Fontes PCR \& Cecon PR (2008c) Produtividade e qualidade de frutos de meloeiro variando número de frutos e de folhas por planta. Horticultura Brasileira, 26:209215.

Queiroga RCF, Puiatti M, Fontes PCR \& Cecon PR (2009) Partição de assimilados em meloeiro cultivado em ambiente protegido com diferentes números de folhas e de frutos. Revista Verde de Agroecologia e Desenvolvimento Sustentável, 4:76-82.

Ribeiro AC, Guimarães PTPG \& Alvarez V VH (1999) Recomendações para uso de corretivos e fertilizantes em Minas Gerais. Viçosa, UFV. 359p.

Rizzo AAN \& Braz LT (2004) Desempenho de linhagens de melão rendilhado em casa de vegetação. Horticultura Brasileira, 22:784788 .

Sakata Seed Sudameria Ltda (2009) Melões. Disponível em: <http:/ /www.sakata.com.br/>. Acessado em: 07 de abril de 2009.

Sang Gyu L, Young Chul K, Tae Cheol S, Yong Gu K, Hyung Kweon Y \& Hyo Duk S (2003) Effects of low light intensity after fruit set on growth and quality of oriental melon (Cucumis melo var. Makuwa Makino). Journal of the Korean Society for Horticultural Science, 44:31-34.

Silva HR \& Costa ND (2003) Melão produção: Aspectos técnicos. Brasília, Embrapa Informação Tecnológica. 225p.

Valentin M, Gary C, Vaissiere BE, Tchamitchian M \& Bruneli B (1998) Changing sink demand affects de area but not specific activity of assimilates sources in cantaloupe. Annals of Botany, 82:711-719.

Valentin M, Vaissiere BE, Gary C \& Robin P (2006) Source-sink balances affects reproductive development and fruit quality in cantaloupe melon. Journal of Horticultural Science \& Biotechnology, 81:105-117. 